Background Pirfenidone is approved in England by NICE for the treatment of Idiopathic Pulmonary Fibrosis (IPF) but its prescription is limited to certain specialised centres. We hypothesised that this may lead to health inequality in the access to the drug per head of population in an area of the Midlands

Methods 2 prescribing centres (PC), and 4 non-prescribing centres(NPC) referring into them were studied. They were the George Eliot Hospital (GEH) in Nuneaton and South Warwick FT (SWFT) in Warwick (both NPCs) referring to University Hospitals of Coventry \& Warwickshire (UHCW) in Coventry, and Kettering General Hospital (KGH) and Northampton General Hospital (NGH), (both NPCs) referring to Glenfield Hospital, University Hospitals of Leicester (UHL).

The number of patients prescribed pirfenidone up to January 2016 was collected, and corrected per 100,000 head of population according to the patient postcode from 2011 census data. All patients were from the CV,LE or NN postcode areas. As data were not normally distributed, analysis was performed with nonparametric statistics using ' $R$ ', a statistics package. We collected the time and distance of travel to patients' local hospital, and to their PC.

Results There were a total of 64 postcode areas (PCAs) in the region. Travel times to local hospitals (either a PC or NPC according to area) were normally distibuted with a median of 19 minutes (range 5-40). Travel time to relevant PC was bimodally distributed, with a median of $261 / 2$ minutes (range 5-64). This was significantly different $\left(\mathrm{p}, 1^{*} 10^{\wedge}-7\right)$. There were no pirfenidone patients in 20 PCAs. Where patients' local hospital was a NPS there were significantly more pirfenidone-free PCAs (15/32) than where the local hospital was a PC (5/32), p $=0.015$. Median number of pirfenidone patients per 100,000 population was significantly less (2.18) where the local hospital was a NPC than where the local hospital was a PC (4.76), $\mathrm{p}=0.019$. There were also significant differences across all 6 hospitals in the median prevalence of pirfenidone prescriptions $(p=0.003)$.

Conclusions Our data suggest there are significant health inequality in access to pirfenidone according to patients' location and whether their local hospital is a PC or not.

\section{P172 DEMOGRAPHIC FACTORS AND TEMPORAL PATTERNS AFFECTING TREATMENT SUCCESS WITH PIRFENIDONE FOR PATIENTS WITH IDIOPATHIC PULMONARY FIBROSIS - A LARGE RETROSPECTIVE REVIEW}

AD Redfern, N Turner, AC Murphy, FA Woodhead. Institute for Lung Health, Glenfield Leicester, UK

\subsection{6/thoraxjnl-2016-209333.315}

Introduction/objectives Idiopathic Pulmonary Fibrosis is progressive with poor outcomes. Evidence from the CAPACITY and ASCEND trials suggests Pirfenidone slows disease progression (Noble et al, 2011; King et al, 2014). We reviewed all patients with more than a year since initiation to assess the proportion that discontinued Pirfenidone for adverse drug reactions (ADRs) or due to unsuccessful treatment $(>10 \% /$ year $\%$ FVC decline or died on therapy), to assess temporal patterns of these stoppages and assess any demographic or disease extent predictors of success (age, sex, BMI, smoking history, \%FVC prediction and FEV1).

Methods 155 patients have been referred to our consultant pharmacist for Pirfenidone initiation since August 2013, of which 65 started and have more than 1 year of data (i.e., we excluded those starting post July 2015). We reviewed hospital databases and medical notes with subsequent data analysis using appropriate parametric statistical methods.

Results 42/65 (64.6\%) stopped therapy overall divided between ADRs (24/42, 57.1\%), FVC decline >10\%/year (11/42, 26.2\%), dying on treatment $(5 / 42,11.9 \%)$ and unclear $(2 / 42,4.8 \%)$. Table 1 demonstrates association between demographics and those that discontinued, suggesting there is one subgroup associated with treatment continuation (patient previously smoked $\mathrm{P} \leq 0.001$ ). The temporal pattern of stopping treatment for ADRs vs those failing for clinical reasons (death on treatment or FVC decline) demonstrated a median cessation time of 40 days vs 226 respectively.

Conclusions Our data suggests two important findings. Firstly, patients' chances of continuing therapy is intriguingly affected positively by smoking history, causation for which remains unclear. Sex, age, BMI or disease extent does not seem to be associated with outcome success. Secondly, those that discontinued for ADRs did so much earlier than those that discontinued due to FVC decline or dying on treatment.

Potential implications for when prescribing Pirfenidone are that we cannot predict those at risk of discontinuation from their demographics. However, a smoking history intriguingly seems to be positively associated with continuation. Additionally, most patients affected by ADRs ceased treatment early, suggesting that if side effects are not noted post early follow up, they are unlikely to occur later. This information improves understanding of prescribing practice for Pirfenidone.

\begin{tabular}{lllll}
$\begin{array}{l}\text { Abstract P172 Table 1 } \\
\text { with therapy continuation }\end{array}$ & Demographic Parameters and association \\
\hline $\begin{array}{l}\text { Demographic } \\
\begin{array}{l}\text { Parameter (mean or } \\
\text { number) }\end{array}\end{array}$ & $\begin{array}{l}\text { Did not } \\
\text { stop } \\
\text { therapy }\end{array}$ & $\begin{array}{l}\text { Stopped due to } \\
\text { Death or FVC } \\
\text { Decline }\end{array}$ & $\begin{array}{l}\text { Stopped due to } \\
\text { Adverse Drug } \\
\text { Reaction }\end{array}$ & $\begin{array}{l}\text { P } \\
\text { (ANOVA } \\
\text { or X') }\end{array}$ \\
\hline $\begin{array}{l}\text { Age at treatment } \\
\text { initiation }\end{array}$ & 69.22 & 68.06 & 72.04 & 0.205 \\
$\begin{array}{l}\text { Sex (M:F) } \\
\text { BMI }\end{array}$ & $20: 3$ & $13: 3$ & $17: 7$ & 0.385 \\
Smoking Hx (Never: & $6: 17$ & $12: 4$ & 23.1 & 0.631 \\
$\begin{array}{l}\text { Ex) } \\
\text { FVC\% predicted }\end{array}$ & 67.39 & 61.88 & $18: 6$ & $<0.001$ \\
FEV1\% predicted & 69.05 & 65.25 & 66.75 & 0.127 \\
\hline
\end{tabular}

\section{P173 REDUCTION IN NON-ELECTIVE RESPIRATORY-RELATED HOSPITALIZATIONS IN PATIENTS TREATED WITH PIRFENIDONE: POOLED ANALYSES FROM THREE PHASE 3 TRIALS OF PIRFENIDONE IN IDIOPATHIC PULMONARY FIBROSIS}

${ }^{1} \mathrm{~B}$ Ley, ${ }^{2} \mathrm{JJ}$ Swigris, ${ }^{3} \mathrm{~B}$ Day, ${ }^{3} \mathrm{~J}$ Stauffer, ${ }^{3} \mathrm{~W}$ Chou, ${ }^{3} \mathrm{~K}$ Raimundo, ${ }^{1} \mathrm{H}$ Collard. ${ }^{1}$ University of California-San Francisco, San Francisco, CA, USA; ${ }^{2}$ National Jewish Health, Denver, CO, USA; ${ }^{3}$ Genentech, Inc., South San Francisco, CA, USA

\subsection{6/thoraxjnl-2016-209333.316}

Rationale Patients with idiopathic pulmonary fibrosis (IPF) are frequently hospitalised for a variety of reasons. Respiratoryrelated hospitalizations may occur because of acute exacerbations of IPF, respiratory tract infections, respiratory failure and other causes. Regardless of cause, respiratory-related hospitalizations have been linked to poor outcomes in patients with IPF. We 
Abstract P173 Table 1 Non-elective Hospitalizations in Patients Treated With Pirfenidone or Placebo over 12 Months

\begin{tabular}{|c|c|c|c|c|c|c|}
\hline \multirow[b]{2}{*}{ Hospitalizations } & \multicolumn{2}{|c|}{ All-Cause Hospitalizations } & \multicolumn{2}{|c|}{ Respiratory-Related Hospitalizations } & \multicolumn{2}{|c|}{ Non-Respiratory Hospitalizations } \\
\hline & $\begin{array}{l}\text { Pirfenidone } \\
(\mathrm{N}=623)\end{array}$ & $\begin{array}{l}\text { Placebo } \\
(\mathrm{N}=624)\end{array}$ & $\begin{array}{l}\text { Pirfenidone } \\
(N=623)\end{array}$ & $\begin{array}{l}\text { Placebo } \\
(\mathrm{N}=624)\end{array}$ & $\begin{array}{l}\text { Pirfenidone } \\
(\mathrm{N}=623)\end{array}$ & $\begin{array}{l}\text { Placebo } \\
(\mathrm{N}=624)\end{array}$ \\
\hline Events, $\mathrm{n}$ & 140 & 147 & 57 & 86 & 83 & 61 \\
\hline \multicolumn{7}{|l|}{ Patients with $\geq 1$ event } \\
\hline $\mathrm{n}(\%)$ & $106(17)$ & $112(18)$ & $44(7)$ & $74(12)$ & $68(11)$ & $51(8)$ \\
\hline Odds ratio $(95 \% \mathrm{Cl})$ & $0.94(0.70,1.26)$ & & $0.56(0.38,0.84)$ & & $1.38(0.94,2.02)$ & \\
\hline$P$-value & 0.662 & & 0.004 & & 0.099 & \\
\hline Died after hospitalisation, $\mathrm{n}(\%)$ & $18(17)$ & $37(33)$ & $12(27)$ & $34(46)$ & $7(10)$ & $9(18)$ \\
\hline
\end{tabular}

describe the proportion of patients from the three Phase 3 pirfenidone IPF trials with at least one non-elective hospitalisation (all-cause, respiratory-related and non-respiratory-related) over 12 months.

Methods In three Phase 3 randomised, placebo-controlled studies of pirfenidone for IPF (CAPACITY I/II and ASCEND), patients were randomised to pirfenidone $(2403 \mathrm{mg} /$ day $)$ or placebo. In the two CAPACITY studies, respiratory-related hospitalizations were a pre-specified endpoint. In ASCEND, hospitalizations were reported as adverse events (AEs), and retrospectively categorised as respiratory-related or non-respiratory by case review. The pooled rates of patients experiencing $\geq 1$ non-elective hospitalizations (all-cause, respiratory-related and non-respiratory-related) for pirfenidone and placebo patients over 12 months are summarised. Rate of death post-hospitalisation was also reported.

Results A total of 1,247 patients (692 CAPACITY and 555 ASCEND) were included (Table). In pooled analyses, the proportion of patients experiencing $\geq 1$ all-cause hospitalizations over 12 months was no different between pirfenidone and placebotreated patients. The proportion of patients experiencing $\geq 1$ respiratory-related hospitalizations was $12 \%$ in the placebo group vs $7 \%$ in the pirfenidone group (odds ratio 0.56; $P=0.004$ ). Deaths after hospitalisation were numerically reduced in the pirfenidone group, most substantially for respiratory-related hospitalizations.

Conclusion Patients with IPF frequently require hospitalisation for a variety of reasons. Pirfenidone may reduce the risk of nonelective respiratory-related hospitalizations over 12 months.

\section{\begin{tabular}{|l|l}
\hline P174 EFFECT OF CONTINUED TREATMENT WITH \\
\hline
\end{tabular} PIRFENIDONE FOLLOWING $A \geq 10 \%$ RELATIVE DECLINE IN PERCENT PREDICTED FORCED VITAL CAPACITY (\%FVC) IN PATIENTS WITH IDIOPATHIC PULMONARY FIBROSIS (IPF)}

\begin{abstract}
${ }^{1} \mathrm{AU}$ Wells, ${ }^{2} \mathrm{C}$ Albera, ${ }^{3} \mathrm{U}$ Costabel, ${ }^{4} \mathrm{G}$ Glaspole, ${ }^{5} \mathrm{MK}$ Glassberg, ${ }^{6} \mathrm{~L}$ Lancaster, ${ }^{7} \mathrm{DJ}$ Lederer, ${ }^{8}$ CA Pereira, ${ }^{9} \mathrm{JJ}$ Swigris, ${ }^{10} \mathrm{~B}-\mathrm{M}$ Day, ${ }^{10} \mathrm{~W}$ Chou, ${ }^{11} \mathrm{SD}$ Nathan. ${ }^{1}$ Royal Brompton Hospital, London, UK; ${ }^{2}$ University of Turin, Turin, Italy; ${ }^{3}$ Ruhrlandkinik, Essen, Germany; ${ }^{4}$ Alfred Hospital, Melbourne, Australia; ${ }^{5}$ University of Miami Miller School of Medicine, Miami, USA; ${ }^{6}$ Vanderbilt University Medical Centre, Nashville, USA; ${ }^{7}$ Columbia University Medical Centre, New York, USA; ${ }^{8}$ Paulista School of Medicine, Federal University of São Paulo, São Paulo, Brazil; ${ }^{9}$ National Jewish Health, Denver, USA; ${ }^{10}$ Genentech Inc, South San Francisco, USA; ${ }^{11}$ Inova Fairfax Hospital, Falls Church, USA
\end{abstract}

\subsection{6/thoraxjnl-2016-209333.317}

Background The variability in disease progression in patients with IPF complicates the assessment of treatment response. Previously a pooled analysis of three Phase 3 trials showed that patients who experienced a $\geq 10 \%$ absolute decline in $\% \mathrm{FVC}$ during the first 6 months of treatment derived a clinical benefit with continued pirfenidone treatment in the subsequent 6 months [Nathan et al. ATS 2015]. To further explore the potential benefit of continued pirfenidone treatment in patients who initially experienced more modest declines, we assessed subsequent outcomes after $\mathrm{a} \geq 10 \%$ relative decline in $\% \mathrm{FVC}$ during the first 6 months of treatment.

Methods Source data included all patients randomised to receive pirfenidone $2403 \mathrm{mg} / \mathrm{d}$ or placebo in the ASCEND or CAPACITY trials $(\mathrm{N}=1247)$. All patients with a $\geq 10 \%$ relative decline in $\%$ FVC were selected by the 6 -month study visit. The proportion of patients in the pirfenidone and placebo groups who experienced any of the following during the subsequent 6month interval were compared: (1) $\geq 10 \%$ relative decline in $\%$ FVC or death; (2) death; or (3) no further decline in \%FVC.

Results Of the pooled patients that experienced an initial $\geq 10 \%$ relative decline in \%FVC, 80 and 140 patients received pirfenidone and placebo, respectively. In the subsequent 6 months, 17 $(21.3 \%)$ and $50(35.7 \%)$ patients, respectively, experienced $\mathrm{a} \geq 10 \%$ relative decline in $\% \mathrm{FVC}$ or death. In addition, more patients in the pirfenidone group had no further decline in $\%$ FVC and fewer patients died compared with placebo during the subsequent 6-month interval (Table 1).

Conclusions In patients who experienced a $\geq 10 \%$ relative decline in \%FVC during the first 6 months of treatment, continued treatment with pirfenidone appeared to lower the risk of \% FVC decline or death during the subsequent 6 months, similar to previous results observed with a $\geq 10 \%$ absolute $\%$ FVC cut-off. Using relative change to calculate a $\geq 10 \%$ initial FVC decline identified more than twice as many patients compared to using absolute change. These findings suggest a potential benefit to continued treatment with pirfenidone despite an initial clinically meaningful decline in FVC $\geq 10 \%$ regardless of calculation method.

Abstract P174 Table 1 Outcomes during the 6-month period following an initial $\geq 10 \%$ relative decline in $\% F V C$ during the first 6 months of treatment

\begin{tabular}{lllll}
\hline Initial $\geq 10 \%$ Relative\%FVC Decline & & & \\
\hline Outcome in subsequent & Pirfenidone & Placebo & Relative & $\begin{array}{l}P \text { - } \\
6 \text { months, } \mathrm{n}(\%)\end{array}$ \\
$(\mathrm{N}=80)$ & $(\mathrm{N}=140)$ & Difference, $\%$ & value \\
$\geq 10 \%$ relative decline in FVC or & $17(21.3)$ & $50(35.7)$ & -40.5 & 0.033 \\
death & & & & \\
Death & $5(6.3)$ & $16(11.4)$ & -45.3 & 0.242 \\
No further decline in FVC & $41(51.3)$ & $50(35.7)$ & 43.5 & 0.033 \\
\hline
\end{tabular}

FVC, forced vital capacity. 